\title{
An Overview of Active Flow Control Enhanced Vertical Tail Technology Development
}

\author{
John C. Lin", Marlyn Y. Andino ${ }^{\dagger}$, Michael G. Alexander \\ NASA Langley Research Center, Hampton, VA, 23681, USA
}

Edward A. Whalen ${ }^{\S}$

The Boeing Company, Boeing Research \& Technology, Hazelwood, MO, 63042, USA

\author{
Marc A. Spoor ${ }^{* *}$, John T. Tran ${ }^{\dagger \dagger}$ \\ The Boeing Company, Boeing Commercial Airplanes, Seattle, WA, 98124, USA
}

Israel J. Wygnanski

The University of Arizona, Tucson, AZ, 85721, USA

\begin{abstract}
This paper summarizes a joint NASA/Boeing research effort to advance Active Flow Control (AFC) technology to enhance aerodynamic efficiency of a vertical tail. Sweeping jet AFC technology was successfully tested on subscale and full-scale models as well as in flight. The subscale test was performed at Caltech on a $\sim 14 \%$ scale model. More than $50 \%$ side force enhancement was achieved by the sweeping jet actuation when the momentum coefficient was $1.7 \%$. AFC caused significant increases in suction pressure on the actuator side and associated side force enhancement. Subsequently, a full-scale Boeing 757 vertical tail model equipped with sweeping jets was tested at the National Full-Scale Aerodynamics Complex 40- by 80-Foot Wind Tunnel at NASA Ames Research Center. There, flow separation control optimization was performed at near flight conditions. Greater than $20 \%$ increase in side force were achieved for the maximum rudder deflection of $30^{\circ}$ at the key sideslip angles $\left(0^{\circ}\right.$ and $\left.-7.5^{\circ}\right)$ with a 31 -actuator AFC configuration. Based on these tests, the momentum coefficient is shown to be a necessary, but not sufficient parameter to use for design and scaling of sweeping jet AFC from subscale tests to full-scale applications. Leveraging the knowledge gained from the wind tunnel tests, the AFC-enhanced vertical tail technology was successfully flown on the Boeing 757 ecoDemonstrator in the spring of 2015.
\end{abstract}

\section{Nomenclature}

$\begin{array}{lll}\mathrm{AFC} & = & \text { active flow control } \\ \mathrm{APU} & = & \text { auxiliary power unit } \\ \mathrm{CFD} & = & \text { computational fluid dynamics } \\ \mathrm{C}_{\mathrm{y}} & = & \text { side force coefficient } \\ \mathrm{C}_{\mathrm{Yn}} & = & \text { normalized side force coefficient relative to baseline (AFC off) } \\ \mathrm{C}_{\mu} & =\text { momentum coefficient, } \% \\ \mathrm{ERA} & =\end{array}$

\footnotetext{
* Aerospace Engineer, Flow Physics and Control Branch, MS 170, AIAA Associate Fellow

† Aerospace Engineer, Flow Physics and Control Branch, MS 170, AIAA Senior Member

* Systems Engineer, Systems Engineering \& Engineering Methods Branch, MS 434

$\S$ Manager, Boeing Research \& Technology, Mail Stop: S306-4030, AIAA Senior Member

** Engineer, Boeing Commercial Airplanes, Technology Integration, Mail Stop: OR-104

† Engineer, Boeing Commercial Airplanes, Stability and Control, Mail Stop: OR-120

\# Professor, Aerospace and Mechanical Engineering Department, AIAA Fellow
} 


$\begin{array}{lll}\mathrm{M}_{\infty} & = & \text { free stream Mach number } \\ \mathrm{NFAC} & = & \text { National Full-Scale Aerodynamics Complex } \\ \mathrm{Re} & = & \text { Reynolds number based on mean aerodynamic chord } \\ \mathrm{U}_{\infty} & = & \text { free stream velocity, knots } \\ \beta & = & \text { sideslip angle, degrees } \\ \beta^{*} & = & \text { normalized sideslip angle (relative to maximum sideslip angle) } \\ \delta_{\mathrm{Rudder}} & = & \text { rudder deflection angle, degrees } \\ \delta^{*} & = & \text { normalized rudder deflection angle (relative to maximum rudder deflection angle) } \\ \% \Delta \mathrm{C}_{\mathrm{y}} & = & \% \text { difference in } \mathrm{C}_{\mathrm{y}} \text { with respect to AFC off, } 100 \% *\left(\mathrm{C}_{\mathrm{y}}-\mathrm{C}_{\mathrm{y}, \mathrm{AFC} \text { off }}\right) / \mathrm{C}_{\mathrm{y}, \mathrm{AFC} \text { off }}\end{array}$

\section{Introduction}

$\mathrm{T}$ HE vertical tail on a modern, multi-engine commercial transport aircraft is sized to overcome the rare instance of engine failure during takeoff and low speed climb that includes crosswind conditions. It must be sufficiently large to generate enough side force to counteract the asymmetric thrust of the operational engine at full power and the drag of the windmilling fan of the failed engine (see Fig. 1) while maintaining directional control. It may, therefore, be oversized during normal operations, particularly for cruise conditions. In addition, the vertical tail is usually sized for the shortest version in an aircraft model family, which effectively makes the common vertical tail oversized for the stretched versions (longer moment arm) in the family. Sized in this way, the vertical tail adds drag and weight that increases the fuel consumption of the entire aircraft family. Active Flow Control (AFC) can be employed to delay flow separation over a highly deflected rudder and increase the side force that it generates. This may enable a smaller vertical tail to provide the control authority needed during an emergency, while still operating in a conventional manner over the rest of the flight envelope. A system integration study indicated that such a design could result in weight and drag reduction and, hence, fuel savings. These benefits are of significant interest to the NASA Environmentally Responsible Aviation (ERA) project. ${ }^{1,2}$

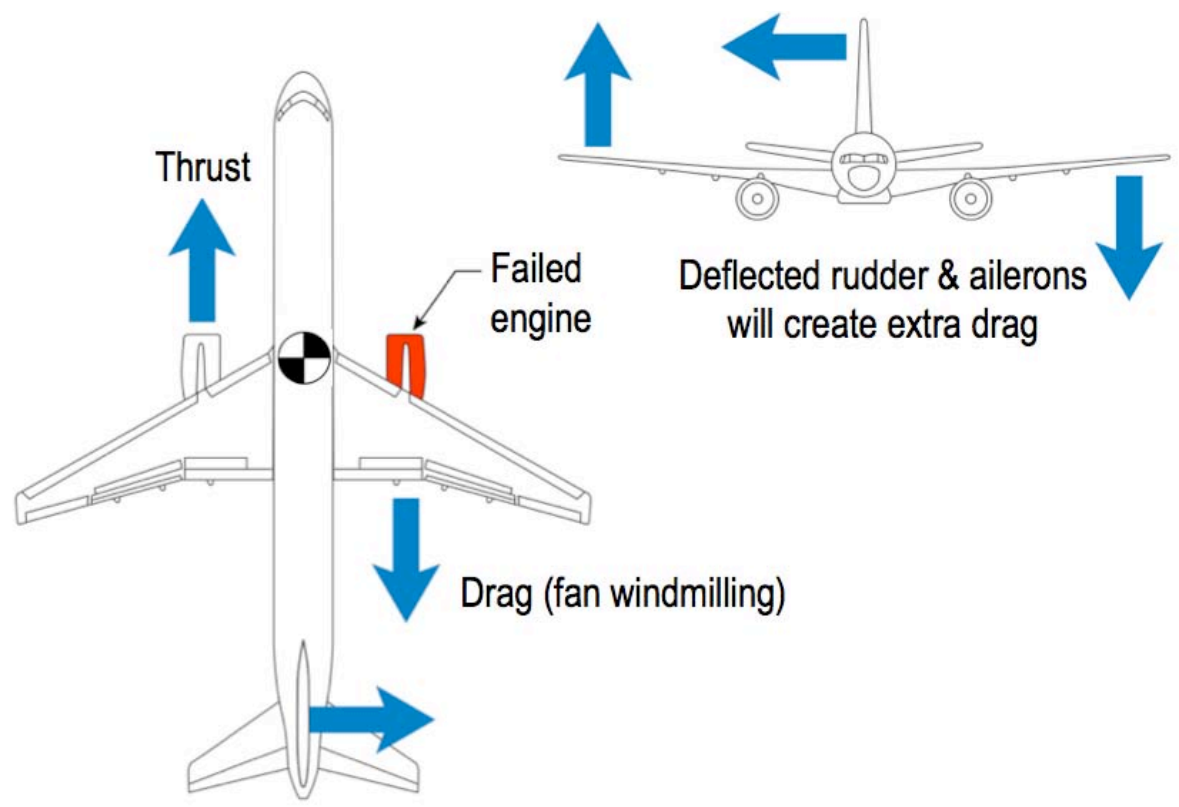

Figure 1. Necessary trim settings of an airplane in case of engine failure.

Various AFC methods have been researched and have shown different degrees of effectiveness for different applications. ${ }^{3}$ For the vertical tail applications, the capabilities of AFC have been tested in wind tunnels on vertical fin models (both subscale and full-scale) and flight-tested on an airplane at relevant conditions. ${ }^{4-13}$ This paper presents an overview of the AFC-enhanced vertical tail technology that was developed by the NASA ERA project, The Boeing Company, and several academic institutions. The goal of the collaboration was to use AFC to achieve a substantial increase in the control authority of the vertical tail of a commercial transport airplane. A timeline and milestone summary chart is presented in Fig. 2, illustrating Technology Readiness Level (TRL) and three phases of technology development: subscale wind-tunnel test, full-scale wind tunnel test, and flight test. 


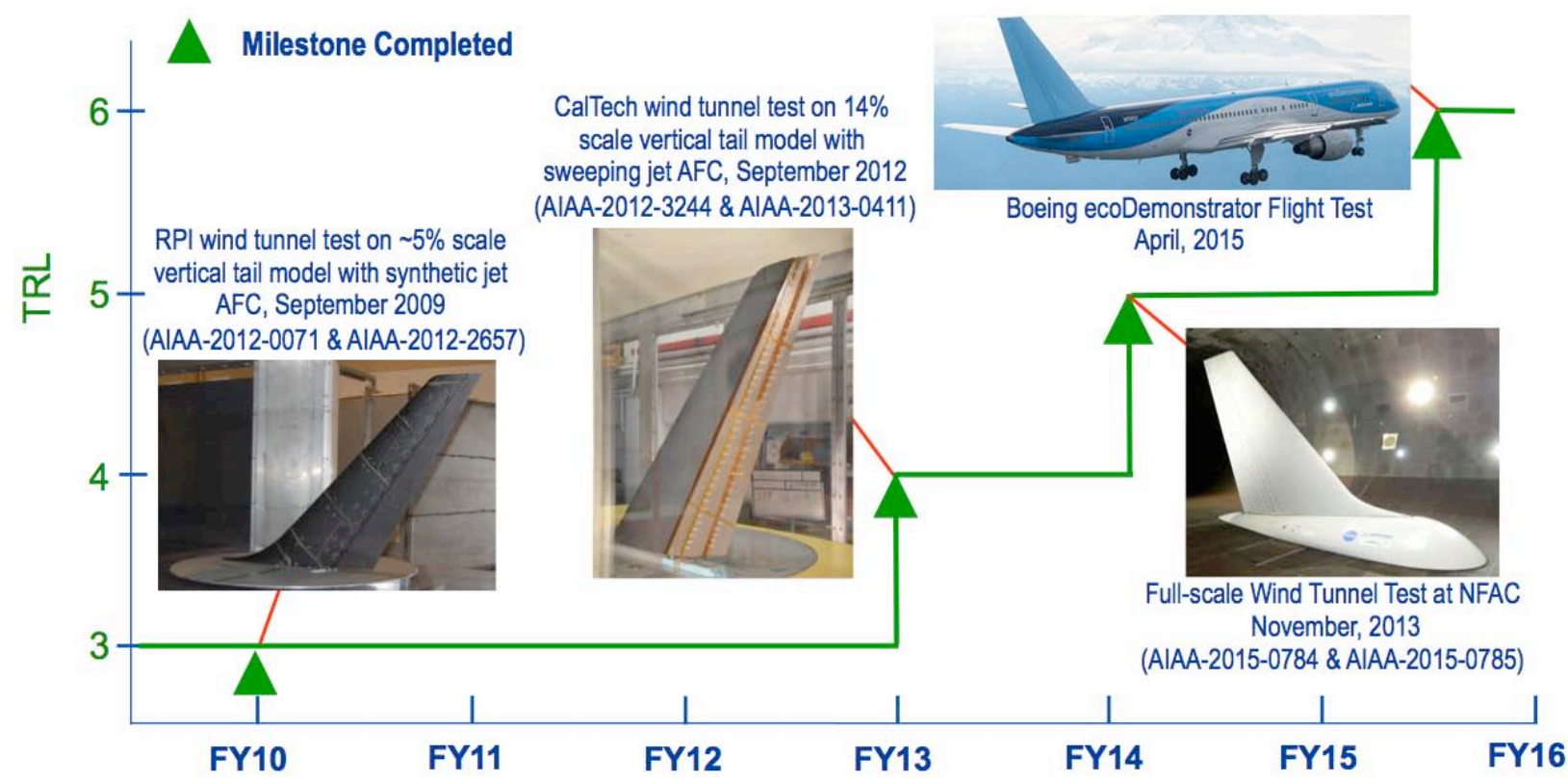

Figure 2. Timeline and milestone completion for AFC-enhanced vertical tail technology.

\section{Subscale Test}

Rathay et al. ${ }^{4-6}$ initially applied synthetic jet actuators to two subscale (4\% and 5\%) vertical stabilizer models at Rensselaer Polytechnic Institute (RPI). Figure 3 (a) shows the 5\% wind-tunnel model being tested at RPI. Synthetic jet actuators placed next to the hinge line of the rudder produced up to $20 \%$ side force increase at moderate rudder deflections $\left(\delta^{*}=0.6, \delta=30^{\circ}\right)$ and zero sideslip $\left(\beta^{*}=0\right)$, as shown in Fig. 3 (b). However, the efficiency of the jets decreases with increasing rudder deflection or sideslip angle because the relatively low amount of momentum $\left(\mathrm{C}_{\mu}=0.248 \%\right)$ is most likely not capable of completely overcoming the flow separation that becomes more severe as the rudder deflection or the sideslip angle increases.

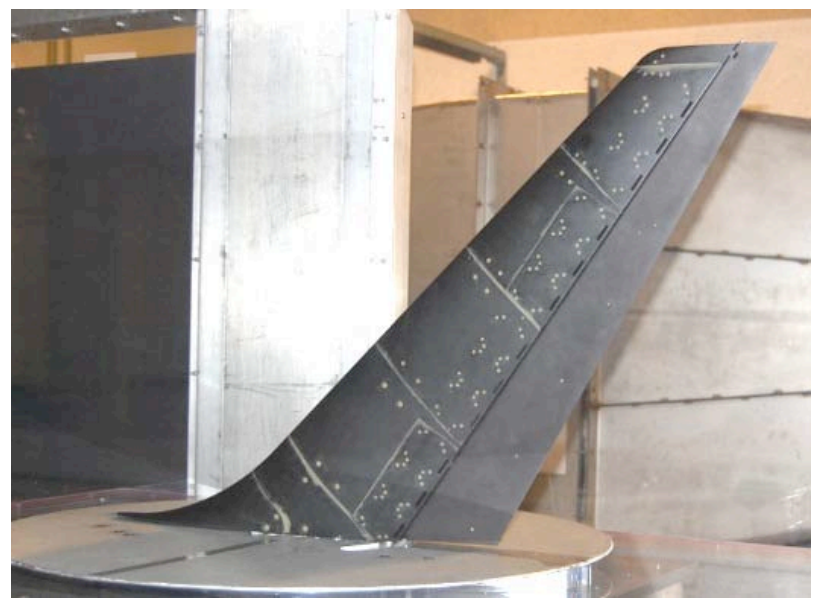

(a) Vertical tail model in RPI wind tunnel.

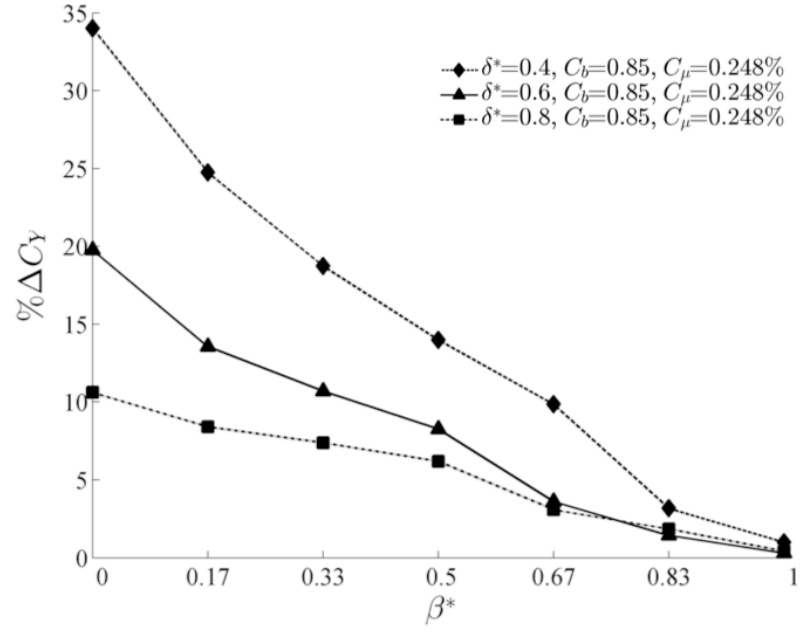

(b) AFC-induced percent side force increase. ${ }^{6}$

Figure 3. Synthetic jet AFC test on a 5\% subscale model.

The use of sweeping jet actuators for AFC is a relatively recent development. They are attractive devices for this kind of application because they require only a steady supply of compressed air. Their sweeping motion energizes the boundary layer over a large surface area and they require no moving parts to do so. A schematic 
drawing of a typical actuator that was reproduced from a paper by Raman and Raghu ${ }^{7}$ is shown in Fig. 4 . Seele et al. ${ }^{8,9}$ applied sweeping jet actuators to a subscale $(\sim 14 \%)$ vertical tail model at Caltech Lucas wind tunnel (see Fig. 5(a)). Thirty-two sweeping jet actuators were placed on the rudder $^{8}$ and on the stabilizer trailing edge, ${ }^{9}$ respectively, in two series of wind tunnel tests. Graff et al. ${ }^{10}$ took the research a step further to incorporate different actuator size and spacing effects and discussed the effects of the sweeping jet actuators on the spanwise flow over swept wings. These three papers ${ }^{8,9}$ reported a significant side force enhancement of approximately $50 \%$ at large rudder deflections $\left(\delta_{\text {Rudder }}=30^{\circ}\right)$, zero sideslip $(\beta)$, and a momentum coefficient $\left(\mathrm{C}_{\mu}\right)$ of $1.7 \%$. A typical example of normalized side force enhancement as a function of $\mathrm{C}_{\mu}$ is shown in Fig. 5(b). Because of their significantly higher $\mathrm{C}_{\mu}$ output and corresponding jet velocity, sweeping jets were selected over the synthetic jets for the subsequent full-scale AFC wind tunnel test. The sweeping jets emanating from the trailing edge of the main element were also selected due to their simpler system integration prospect.

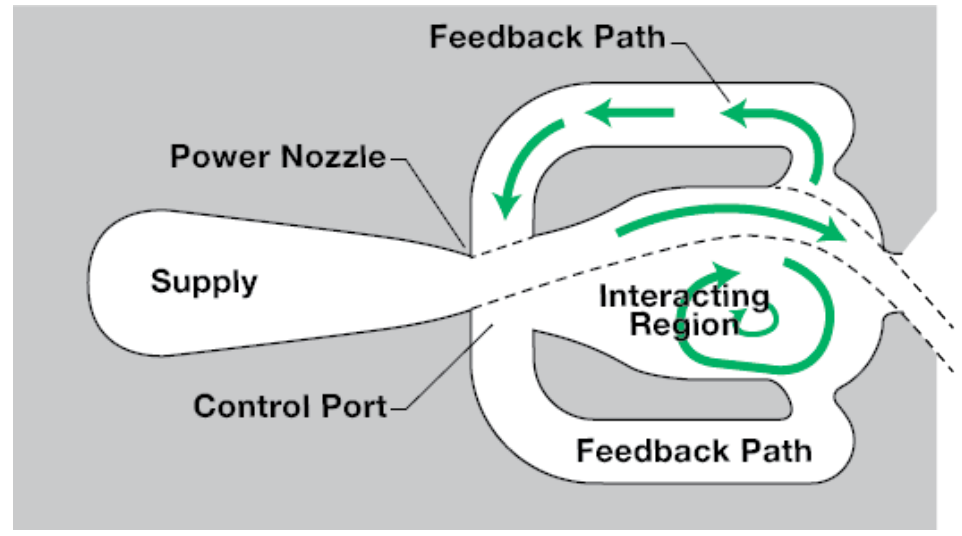

Figure 4. Conceptual design of sweeping jet actuator. ${ }^{7}$

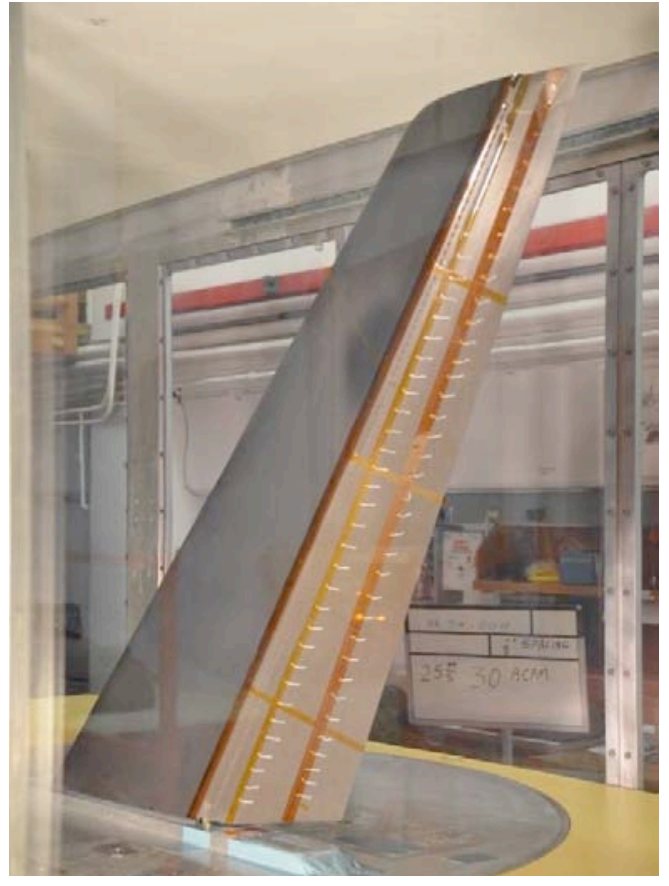

(a) Vertical tail model in Caltech wind tunnel.

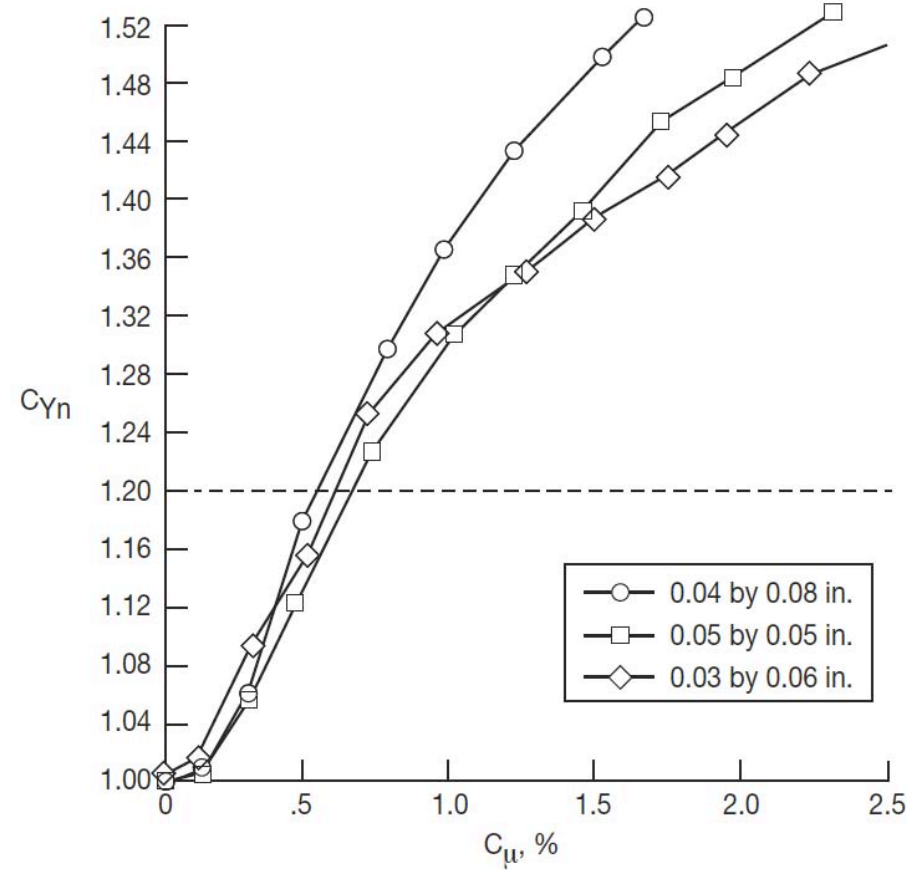

(b) AFC-induced percent side force increase versus momentum coefficient at $\mathrm{U}_{\infty}=40 \mathrm{~m} / \mathrm{s}, \delta_{\text {Rudder }}=30^{\circ}$ and $\beta=0^{\circ}$.

Figure 5. Sweeping jet AFC test on a $14 \%$ subscale model. ${ }^{9}$ 


\section{Full-Scale Test}

Following the Caltech test, Boeing acquired a 757 vertical tail from an aircraft boneyard, Evergreen Air Center (Fig. 6), near Tucson, AZ, and modified it to be used as a wind tunnel model at the NFAC 40x80 wind tunnel. ${ }^{14}$ The approximately 25 - $\mathrm{ft}$ tall, flight-hardware tail was installed on top of a blister fairing inside the tunnel test section (Fig. 6). The full-scale vertical tail model was tested at a nominal speed of 100 knots $\left(\mathrm{M}_{\infty} \sim 0.15, \operatorname{Re} \sim 15\right.$ million), a maximum speed of 130 knots $\left(\mathrm{M}_{\infty} \sim 0.2, \mathrm{Re} \sim 20\right.$ million $)$, and across the vertical tail flight envelop for rudder deflections $\left(0^{\circ}\right.$ to $\left.30^{\circ}\right)$ and sideslip angles $\left(0^{\circ}\right.$ to $\left.-7.5^{\circ}\right) .^{11,12}$
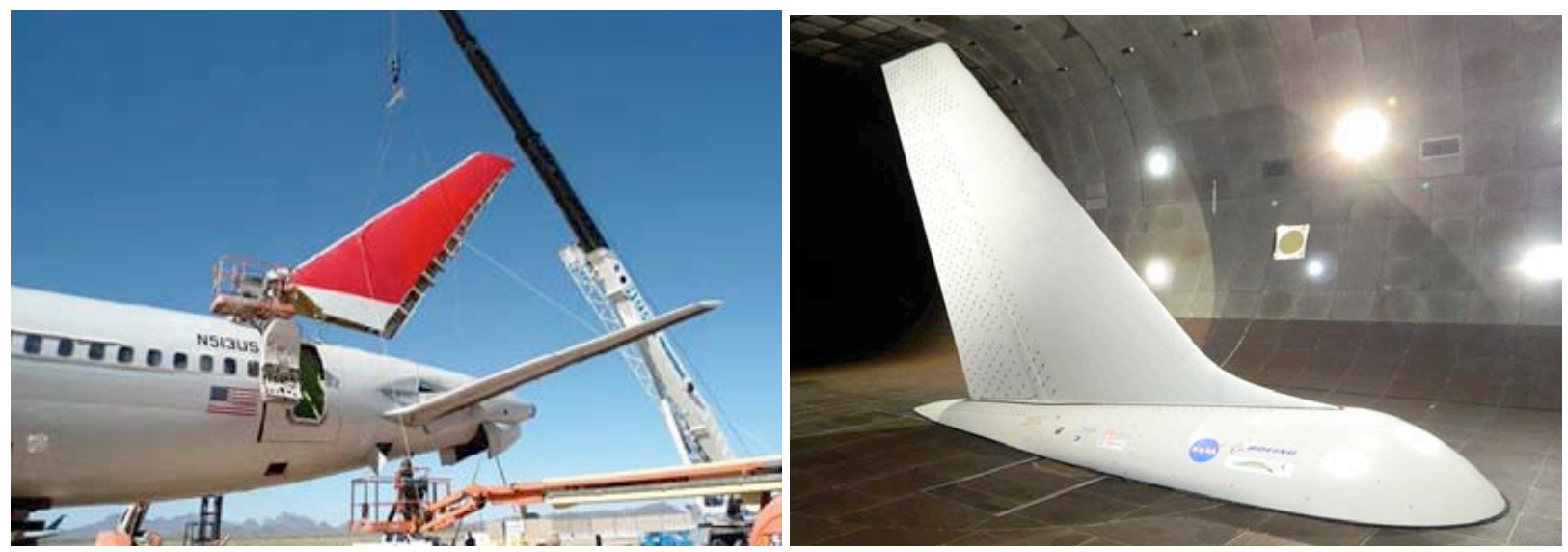

Figure 6. Boeing 757 vertical tail being removed at Evergreen Air Center (left) and the tail model installed on top of a blister fairing in the NFAC 40x80 wind tunnel (right). ${ }^{11}$

NASA personnel, using the technical support obtained from the California Institute of Technology (Caltech) and the University of Arizona, adapted the sweeping jet AFC system used in the subscale tests to the full-scale model. There were 37 sweeping jet actuators evenly spaced across the starboard span at the trailing edge of the main element. A pressure regulator valve independently controlled the supply air pressure to each actuator. The installation of the sweeping jet actuators is illustrated in Fig. 7. The internal geometry of each actuator is illustrated in Fig. 4. Each actuator has a nozzle width-to-height ratio of 2 and the spacing between each actuator is 16.7 times the nozzle width. Tuft flow visualization, aerodynamic force and moments, and corresponding AFC system data were acquired on the full-scale vertical tail model.
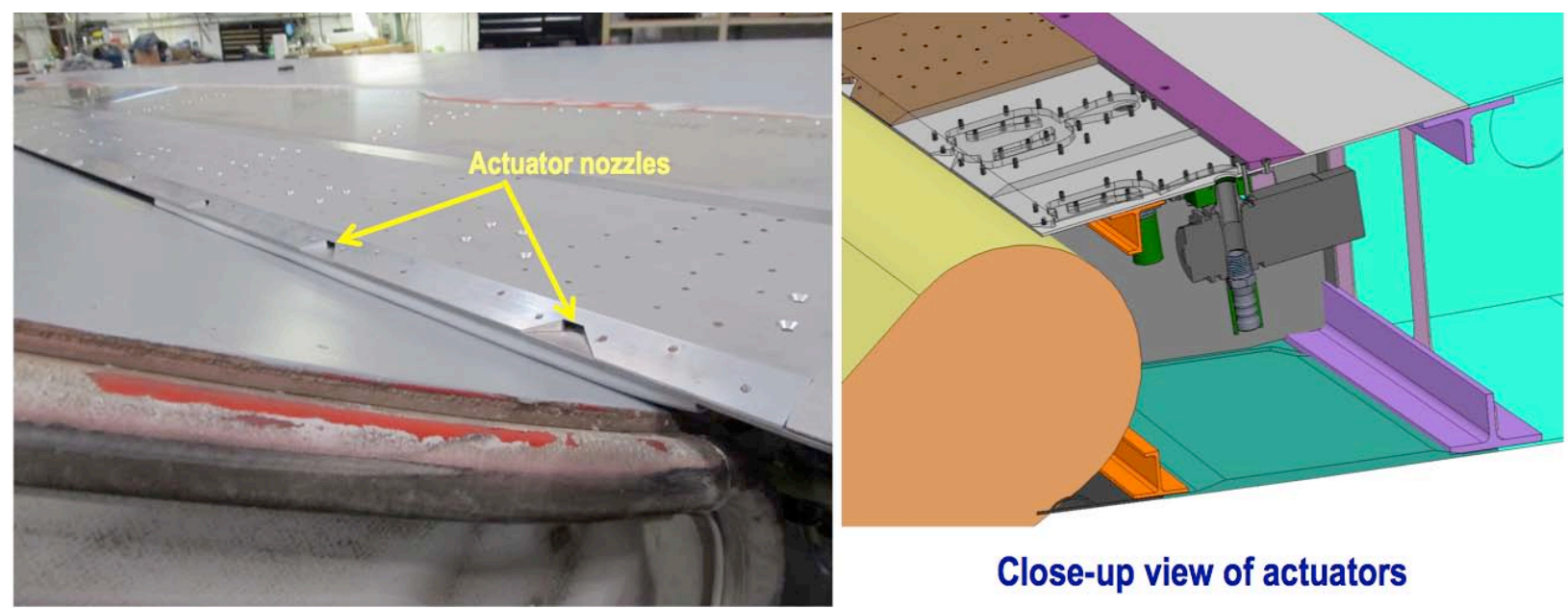

Close-up view of actuators

Figure 7. Sweeping jet actuator installation on the full-scale model. ${ }^{11}$

Various actuation configurations were examined by using the pressure regulator valves to individually control the mass flow of each actuator. For example, turning off individual actuators varied the actuator spacing. Similarly, the effect of regions of actuation was explored by turning off actuators near the root and/or the tip regions. Actuator configurations were evaluated based on their side force enhancement performance at $\delta_{\text {Rudder }}=30^{\circ}$ (maximum rudder deflection that was used on the airplane and thus the limit for the test) and $U_{\infty}=100$ knots. A number of actuator 
configurations produced a significant increase in side force (i.e., 20\%) at maximum rudder deflection and at the target sideslip angles $\left(0^{\circ}\right.$ and $\left.-7.5^{\circ}\right)$. Note that in the stability and control coordinate system used, positive rudder deflection and negative sideslip angle result in positive side force.

Figures 8(a) and 8(b) show the percentage of the side force coefficient increase $\left(\% \Delta \mathrm{C}_{\mathrm{y}}\right)$ as a function of $\mathrm{C}_{\mu}$ for sideslip angle $(\beta)$ of $0^{\circ}$ and $-7.5^{\circ}$, respectively. The $\% \Delta \mathrm{C}_{\mathrm{y}}$ of each plot in Fig. 8 is normalized by the baseline (AFC off) side force coefficient at its respective $\beta$. The theoretical inviscid performance of the vertical tail without AFC (calculated using CFD) is also shown for $\beta=0^{\circ}$ for comparison (Fig. 8(a)). It is considered as being an indicator of system efficiency for flow separation control. A $20 \%$ increase in side force was selected as a performance goal based on earlier system integration studies and is indicated by the blue dashed line on both plots. The $\% \Delta \mathrm{C}_{\mathrm{y}}$ versus $\mathrm{C}_{\mu}$ curves roughly collapsed onto a single band of curves for each respective $\beta$. However, there were some subtle differences. Most striking is that 31 actuators provided larger side-force increments than the 37-actuator case at moderate to high momentum coefficients, as did 18 actuators. A similar behavior was observed at $-7.5^{\circ}$ sideslip. Figure 8(a) shows that several actuator configurations could meet the $20 \%$ side force increase at $\beta=0^{\circ}$ with $\mathrm{C}_{\mu}$ greater than $\sim 0.3 \%$. Comparing the full-scale results of Fig. 8 (a) to the subscale results of Fig. 5 (b), which show a similar trend, one can conclude that $\mathrm{C}_{\mu}$ is a reasonable parameter to use for scaling-up sweeping jet AFC from subscale tests to full-scale applications.

Figure 8(b) shows an additional $\Delta \mathrm{C}_{\mu}$ of approximately $0.2 \%\left(\mathrm{C}_{\mathrm{y}}\right.$ increased by a factor of 1.67$)$ was needed to achieve the $20 \%$ side force enhancement due to the higher baseline (AFC off) value of $C_{y}$ at $\beta=-7.5^{\circ}$. Although a number of actuator configurations (actuator number $\geq 12$ ) could meet the $20 \% \Delta \mathrm{C}_{\mathrm{y}}$ at $\beta=0^{\circ}$, only the 37- and 31actuator configurations could meet the performance standard with certainty at $\beta=-7.5^{\circ}$ for $\mathrm{C}_{\mu} \leq 0.6 \%$. The 31actuator configuration was achieved through deactivating 6 actuators from the tip. The tip actuation removal results are consistent with the subscale test result reported by Seele et al. ${ }^{9}$ where up to around $15 \%$ of the AFC coverage could be removed from the tip without significant performance degradation. This reduced-actuator configuration exhibited greater side force enhancement compared to the 37-actuator configuration and did so with less mass flow, lower momentum, and a potentially simpler plumbing system. Therefore, it was selected as the AFC configuration for the follow-on flight test.

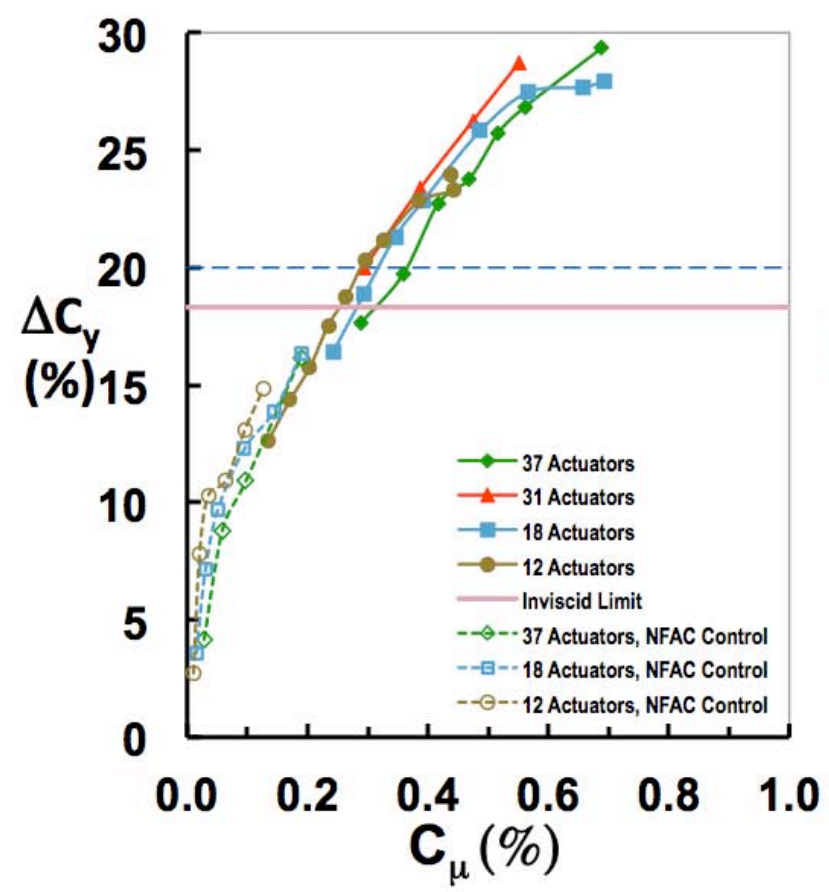

(a) $\beta=0^{\circ}$

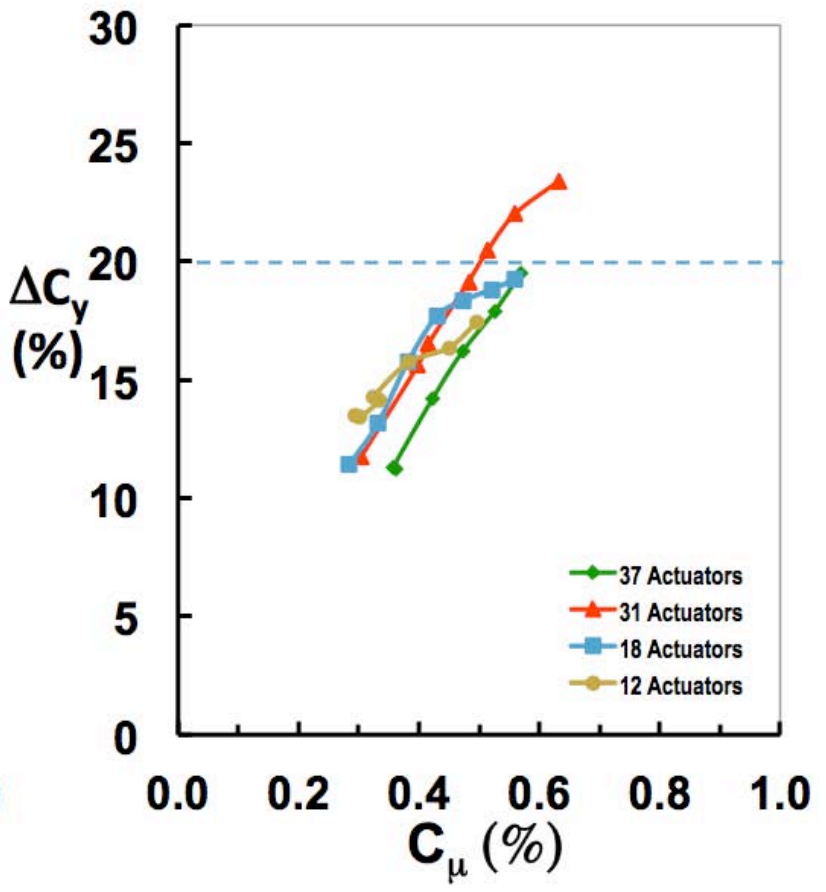

(b) $\beta=-7.5^{\circ}$

Figure 8. Side force enhancement versus momentum coefficient ( $\delta_{\text {Rudder }}=30^{\circ}, U_{\infty}=100$ knots $) .{ }^{12}$

Tuft flow visualization confirmed the effectiveness of the selected AFC configuration. Figures 9(a) and 9(b) show the tuft directions for (a) baseline and (b) when 31 actuators were on. In Fig. 9, the yellow arrow indicates the general flow direction on the rudder and the red triangles indicate the approximate location of sweeping jet nozzles. Figure 9(a) shows the tufts on the rudder pointing mostly upward toward the tip and they also rotated violently for 
the baseline case, while Fig. 9(b) shows the tufts are steadier (therefore they have a thicker image) and they point downstream for the AFC attached flow. Notice the spanwise flow toward the tip downstream of the region where 6 actuators were deactivated (as indicated by the orange oval) because of their close proximity to the tip vortex. The effect of those actuators on the side force generated by the rudder was minimal, and therefore they could be eliminated. This flow visualization suggests that turning the flow inboard, toward the direction of the free stream, improves the control authority of the rudder.

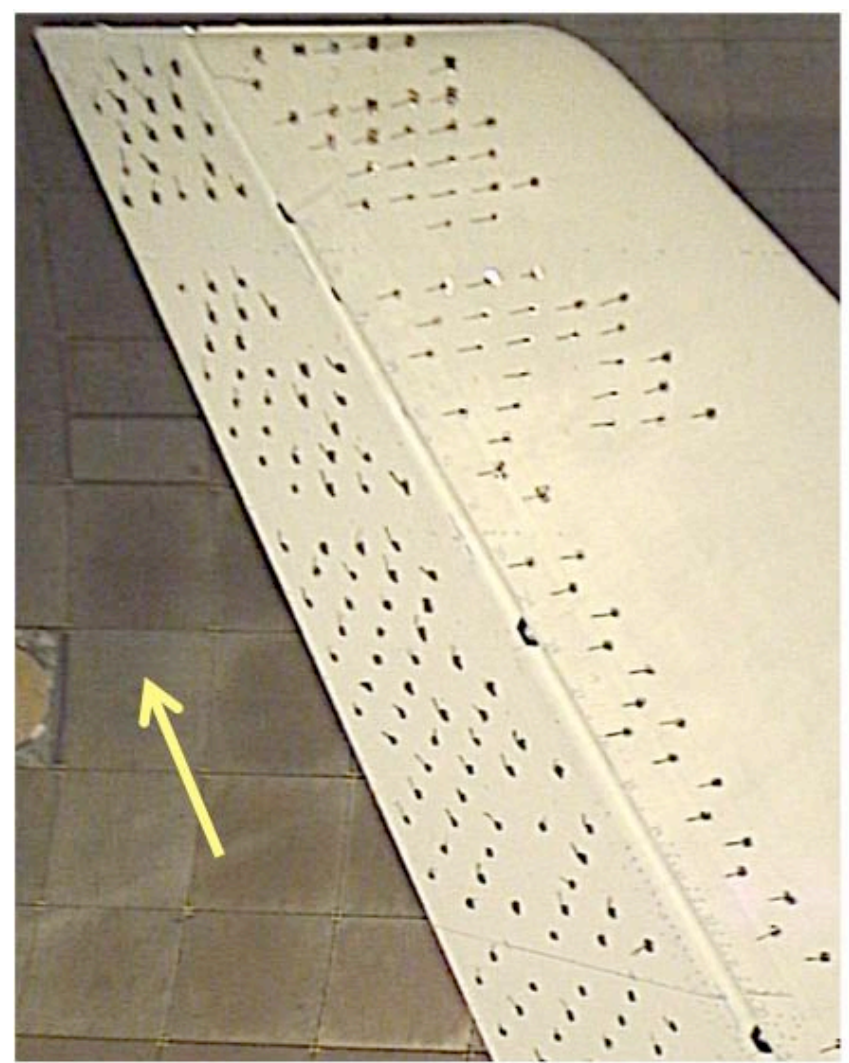

(a) Baseline (AFC off)

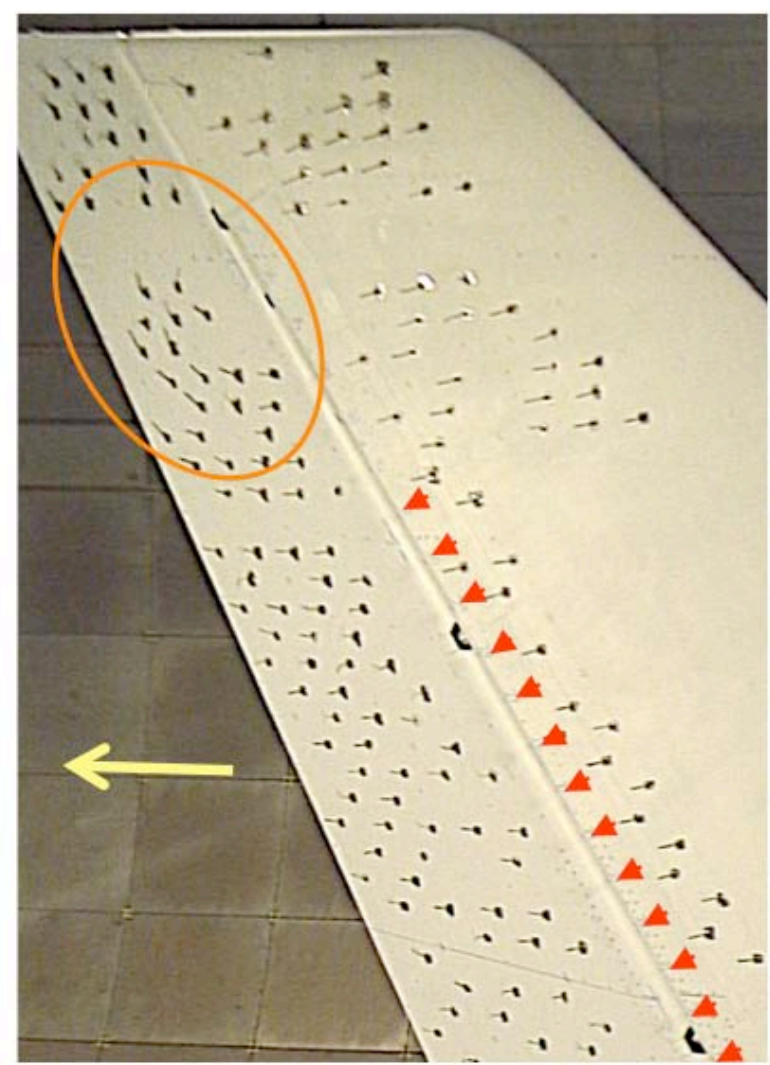

(b) 31 actuators (AFC on)

Figure 9. Flow visualization using tufts on the AFC side of vertical tail $\left(\delta_{\text {Rudder }}=30^{\circ}, \mathrm{U}_{\infty}=100 \mathrm{knots}, \beta=0^{\circ}\right) .^{12}$

The surface pressure contours for the baseline and the 31-actuator case are shown in Fig 10(a) to further visualize and quantify the effectiveness of $\mathrm{AFC}$ on the vertical tail for $\delta_{\text {Rudder }}=30^{\circ}, \mathrm{U}_{\infty}=100$ knots, and $\beta=0^{\circ}$. For illustration standardization purposes, the images of the pressure contours are flipped from those of Fig. 9 such that the flow direction here is from left to right. An " $x$ " indicates the pressure tap location, the small red rectangular boxes represent geometrical openings on the leading edge, and an "o" indicates the location of an active actuator. Sweeping jet actuation increased the suction pressure along the rudder hinge line and it did so across almost the entire span. Pressure contours for the AFC case also indicated a better pressure recovery near the trailing edge. The AFC-induced attached flow is fairly uniform across the rudder span.

Similarly, Fig. 10(b) presents the corresponding pressure contours of Fig. 10(a) at $\beta=-7.5^{\circ}$ where the suction pressure magnitude along the leading edge of the vertical tail model increased significantly with the increased negative sideslip angle. The high magnitude of the suction pressure near the leading edge dominates the entire pressure contour. The $\mathrm{C}_{\mathrm{p}}$ range was truncated to provide better resolution in the area of interest, i.e., the rudder and its shoulder region. Similar to the $0^{\circ}$ sideslip case, the AFC appears to affect the pressure distribution most significantly near the rudder shoulder. Improved pressure recovery at the trailing edge of the rudder is also apparent, indicating that separation has been reduced. The biggest difference between the two sideslip angles is the shifting of the suction peak from the hinge-line location for zero sideslip $\left(\beta=0^{\circ}\right)$ to the main element leading-edge location for $\beta=-7.5^{\circ}$. The increased suction pressure farther downstream along the rudder hinge line at both sideslip angles with AFC applied should increase the distance between the tail aerodynamic center and the center of the gravity of the aircraft, which should provide an increase in yaw control authority. 

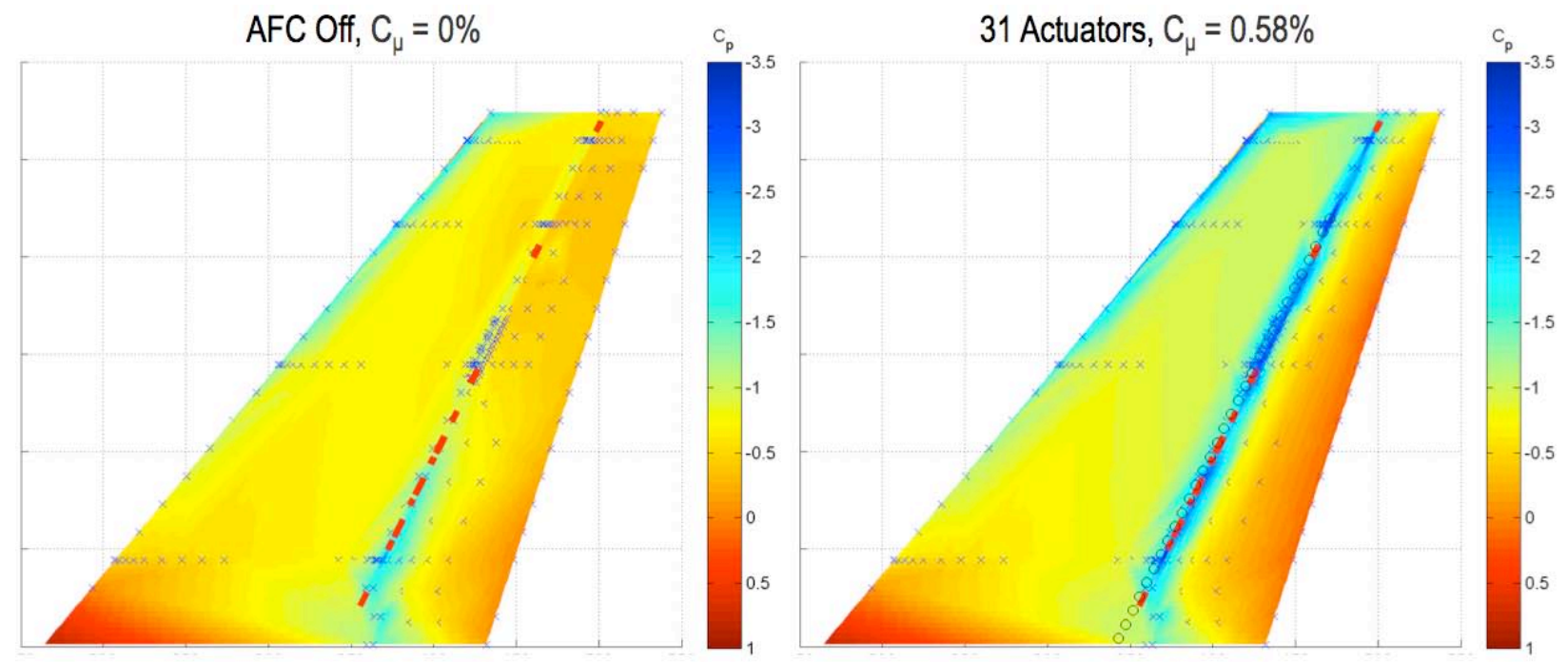

(a) $\beta=0^{\circ}$
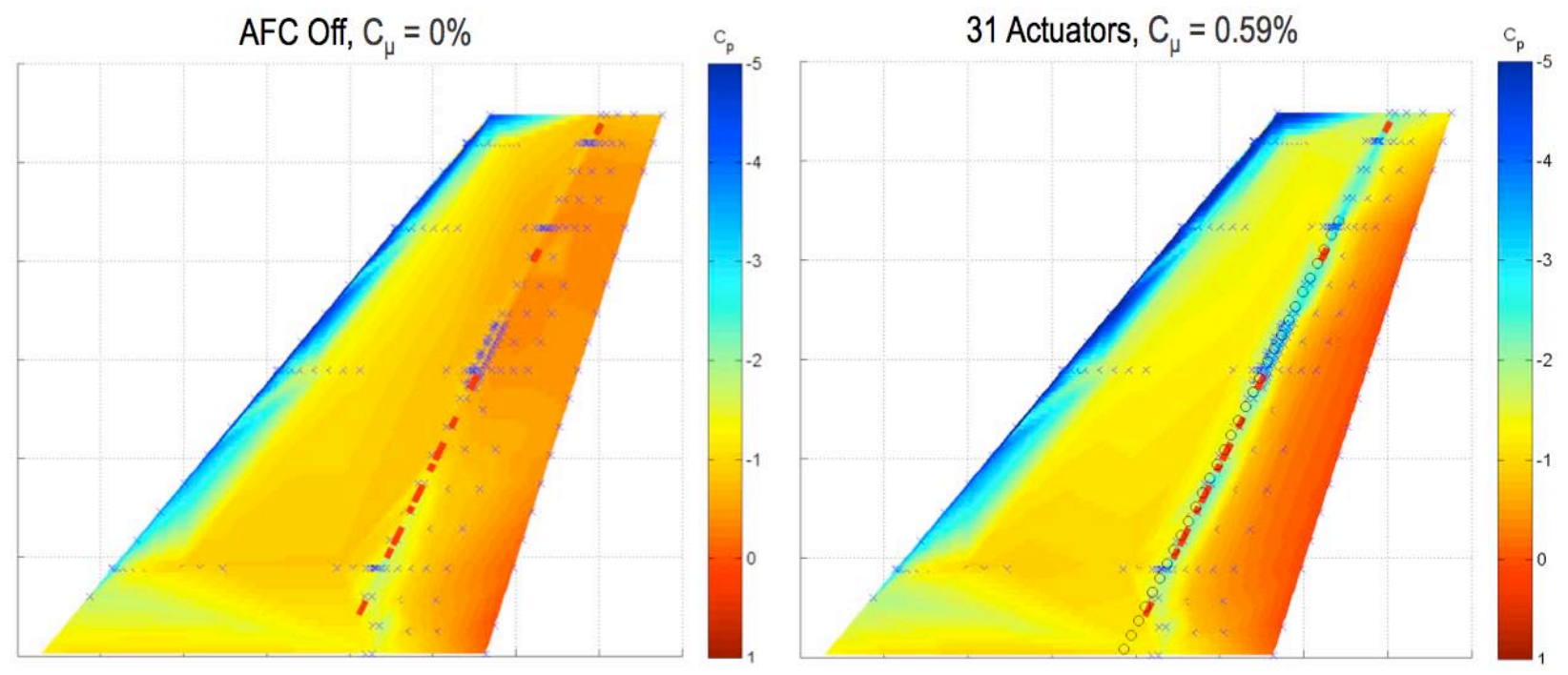

(b) $\beta=-7.5^{\circ}$

Figure 10. Pressure contours on the AFC side of vertical tail $\left(\delta_{\text {Rudder }}=30^{\circ}, U_{\infty}=100\right.$ knots $) .{ }^{12}$

As part of the test campaign, the performance effects of vortex generators (VGs) were compared to those of the sweeping jet actuators. Vortex generators are typically used on vertical tails for reasons similar to those described for the sweeping jets. Figures 11 (a) and $11(\mathrm{~b})$ present percent side force increase $\left(\% \Delta \mathrm{C}_{\mathrm{y}}\right)$ versus rudder deflection at $\mathrm{U}_{\infty}=100$ knots for $\beta=0^{\circ}$ and $-7.5^{\circ}$, respectively, for the best AFC and the best VG cases. The VGs are moderately successful in providing side force enhancement (up to $\sim 10 \%$ ), however, their effectiveness levels off at $\delta_{\text {rudder }}=27.5^{\circ}$ and $25^{\circ}$ for $\beta=0^{\circ}$ and $-7.5^{\circ}$, respectively. Comparing the effects of the VGs to the 31-actuator case shows that the sweeping jets provided more than twice the side force increase of the best VG configuration at maximum rudder deflection and zero sideslip. The differences between them are even more dramatic at $\beta=-7.5^{\circ}$ and large rudder deflections $\delta_{\text {rudder }} \geq 25^{\circ}$ where the sweeping jets performed more than four times better than the best VG configuration. The 31-actuator configuration significantly increased side force (by greater than 20\%) at the maximum rudder deflection of $30^{\circ}$ for both sideslip angles investigated. 


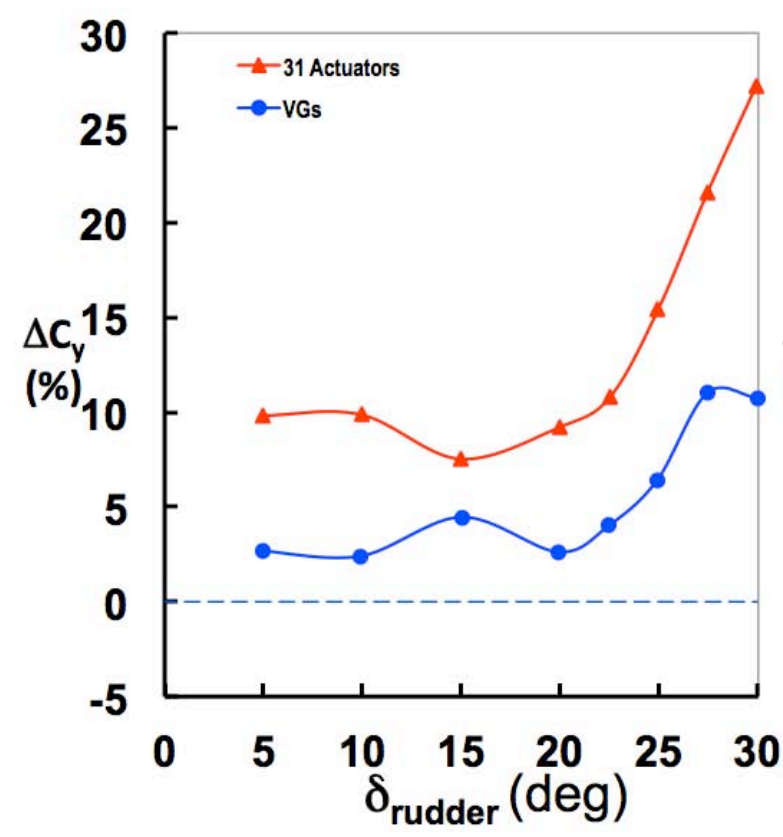

(a) $\beta=0^{\circ}$

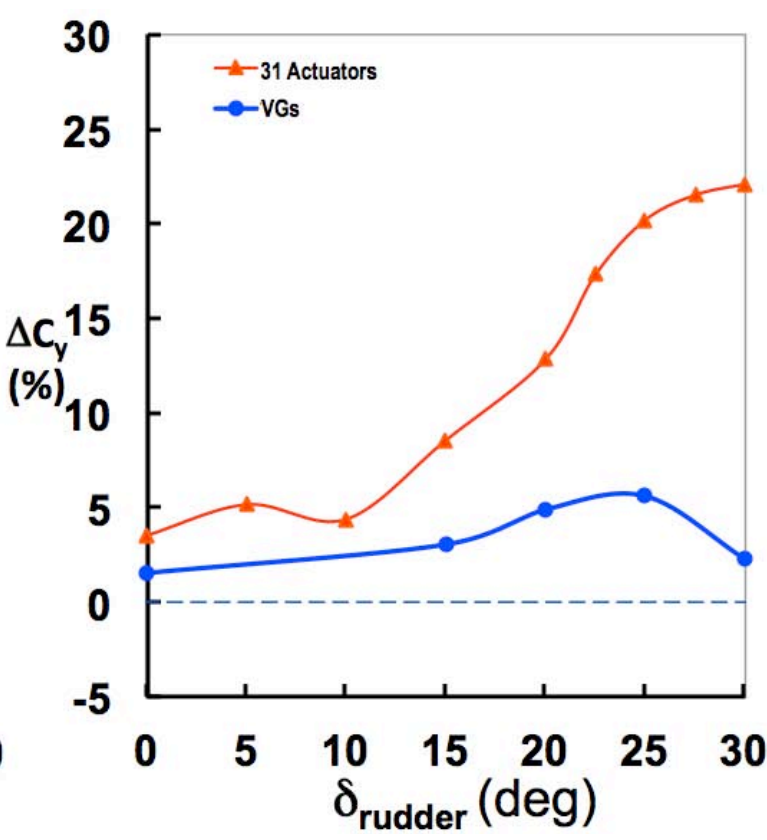

(b) $\beta=-7.5^{\circ}$

Figure 11. Side force enhancement versus rudder deflection for comparison with VGs $\left(U_{\infty}=100 \mathrm{knots}\right){ }^{11}$

\section{Flight Test}

An AFC-enhanced vertical tail flight test was performed in the spring of 2015 on a specially outfitted Boeing 757 airplane called the 757 ecoDemonstrator. ${ }^{13}$ Leveraging the knowledge gained from the full-scale wind-tunnel test at NFAC, the NASA ERA project team worked with Boeing to install 31 sweeping jet actuators on the starboard side of the vertical tail of the 757 ecoDemonstrator. The objectives of the flight test were to demonstrate integration of an AFC system into an airframe and thereby highlight challenges for technology transition, measure AFC impact on rudder effectiveness in flight, and collect in-flight data for comparison to full-scale wind tunnel results and CFD predictions. These flights included maneuvers such as steady heading sideslips as well as simulated engine-out trims and engine-out decelerations to measure the effect of the AFC. Variations in sweeping-jet arrangements and flow rates were also explored during the flight test.

For the flight test, the AFC modifications were installed into the stabilizer and aft fuselage. Bleed air from the Auxiliary Power Unit (APU) compressor provided system mass flow. An air-to-air heat exchanger was mounted underneath the aft body of the airplane to cool the APU air to comply with stabilizer and rudder structural requirements. Ducting within the fuselage routed the air to ducting embedded in the stabilizer. The ducting in the fin branched into smaller tubes to bring the air to panel-mounted AFC nozzles. The 31 sweeping jet nozzles (exits) were located along the hinge line on the starboard (right) side of the trailing edge of the stabilizer, where the nozzles were aligned normal to the trailing edge and pointed downstream. An external view of the AFC configuration is shown in Fig. 12. The red dashed line shows the upstream end of the AFC actuator. The actuator numbers are placed just upstream of the actuator nozzles, and the white dots located primarily on the rudder are for flow visualization cones.

Instrumentation on board the ecoDemonstrator flight-test airplane were used to evaluate the performance of the AFC-enhanced vertical tail in several flights over the Strait of Juan de Fuca, just north of Seattle, Washington. Figures 13 (a) and 13 (b) illustrate the 757 ecoDemonstrator airplane with AFC modifications during various portions of the test program.

The flow cone photos from the chase plane were digitally overlaid to provide a snapshot of the flowfield during a given test condition. The attach points of each cone were aligned in the composite photo. Generally these photos represent one second of time and combine approximately five individual photos. Figure 14 illustrates the difference in the flow field when AFC is off and when it is on. When off, the cone orientation at many locations on the vertical fin does not coincide with the cone orientation in previous or subsequent photos taken within a fraction of a second of each other. This spreading or scattering in the composite photo indicates unsteady flow. When AFC is on, the cones from one picture to the next nearly coincide, indicating that AFC is reducing the separated flow over the rudder surface. Pilot feedback also confirmed the effectiveness of AFC, as smoother flight and enhanced rudder control authority were achieved. 

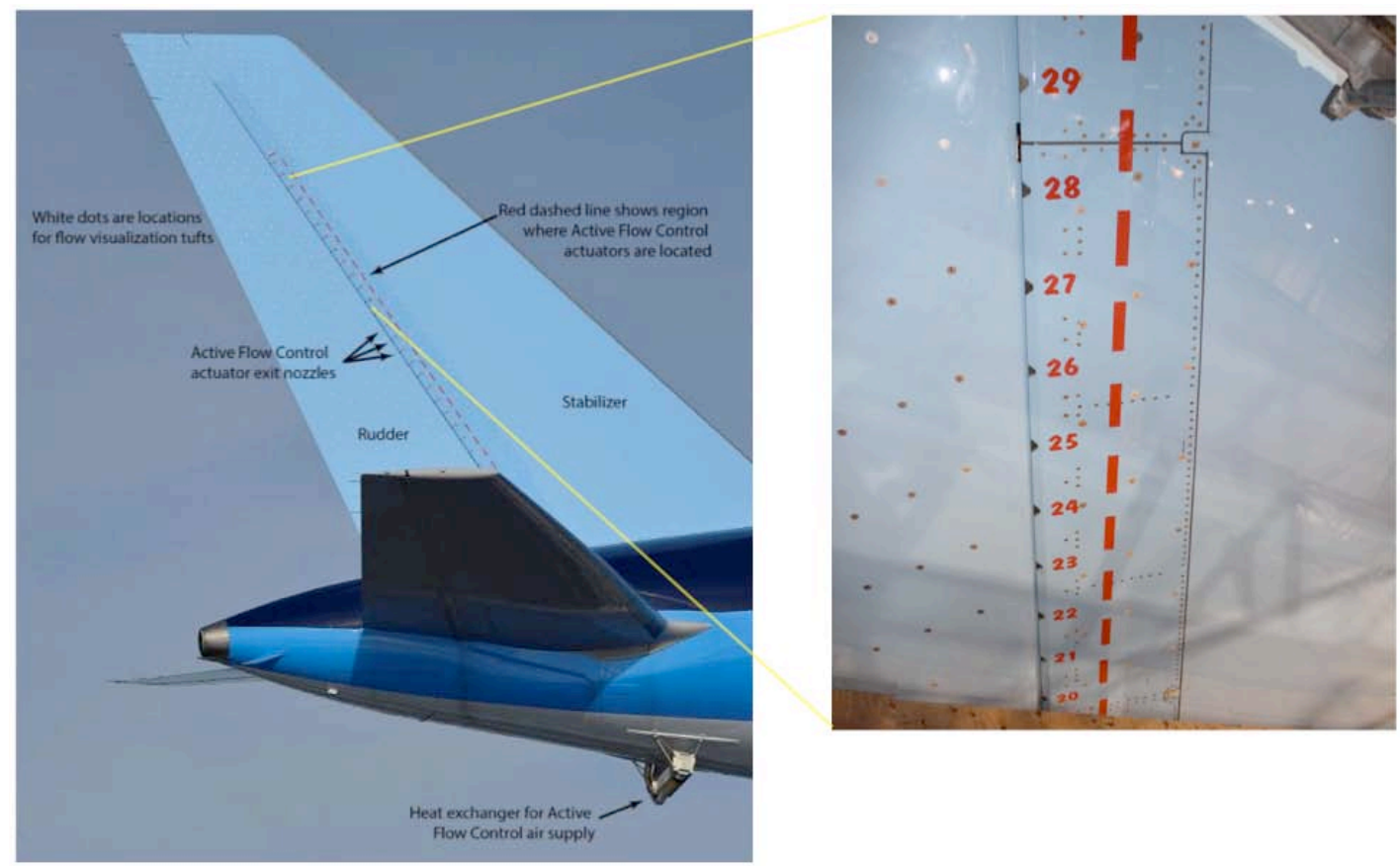

Figure 12. Sweeping jet actuator arrangement on the 757 vertical tail.

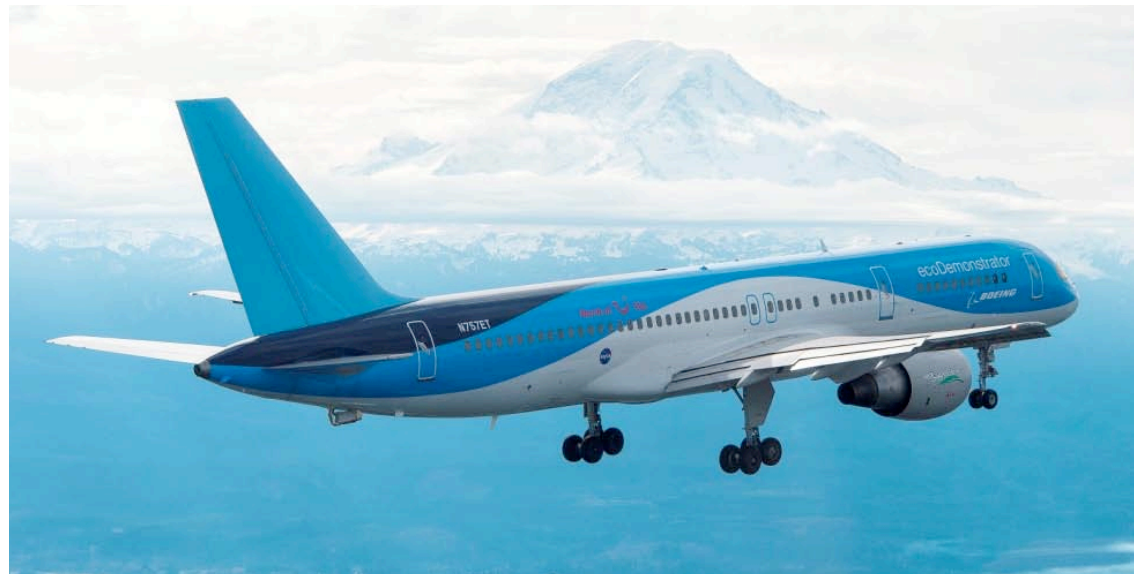

(a) 757 ecoDemonstrator during Functional Check Flight.

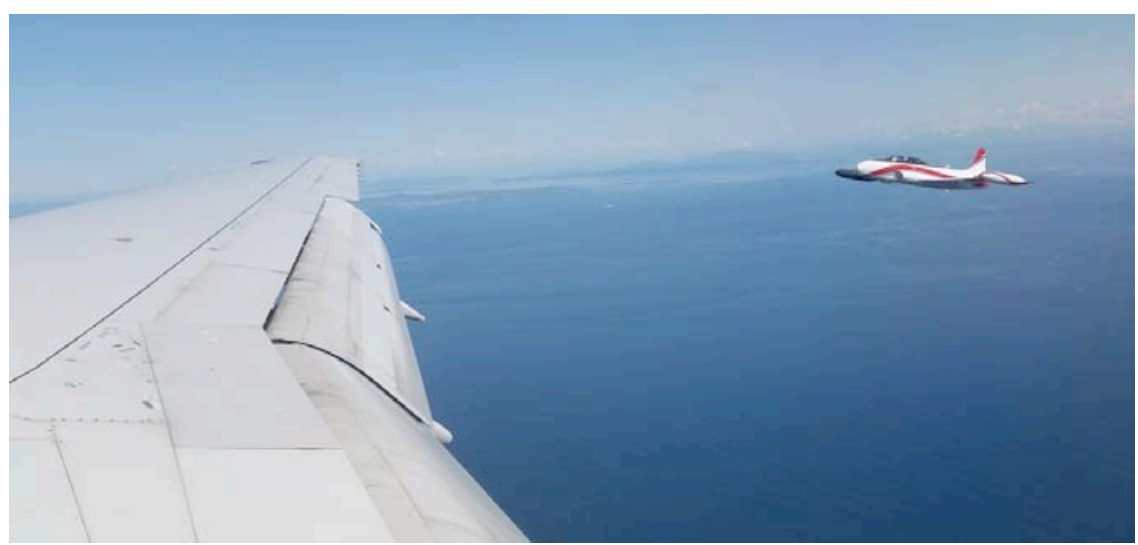

(b) Boeing T-33 Chase Plane providing photo support during flight test.

Figure 13. Boeing 757 ecoDemonstrator during flight test. 


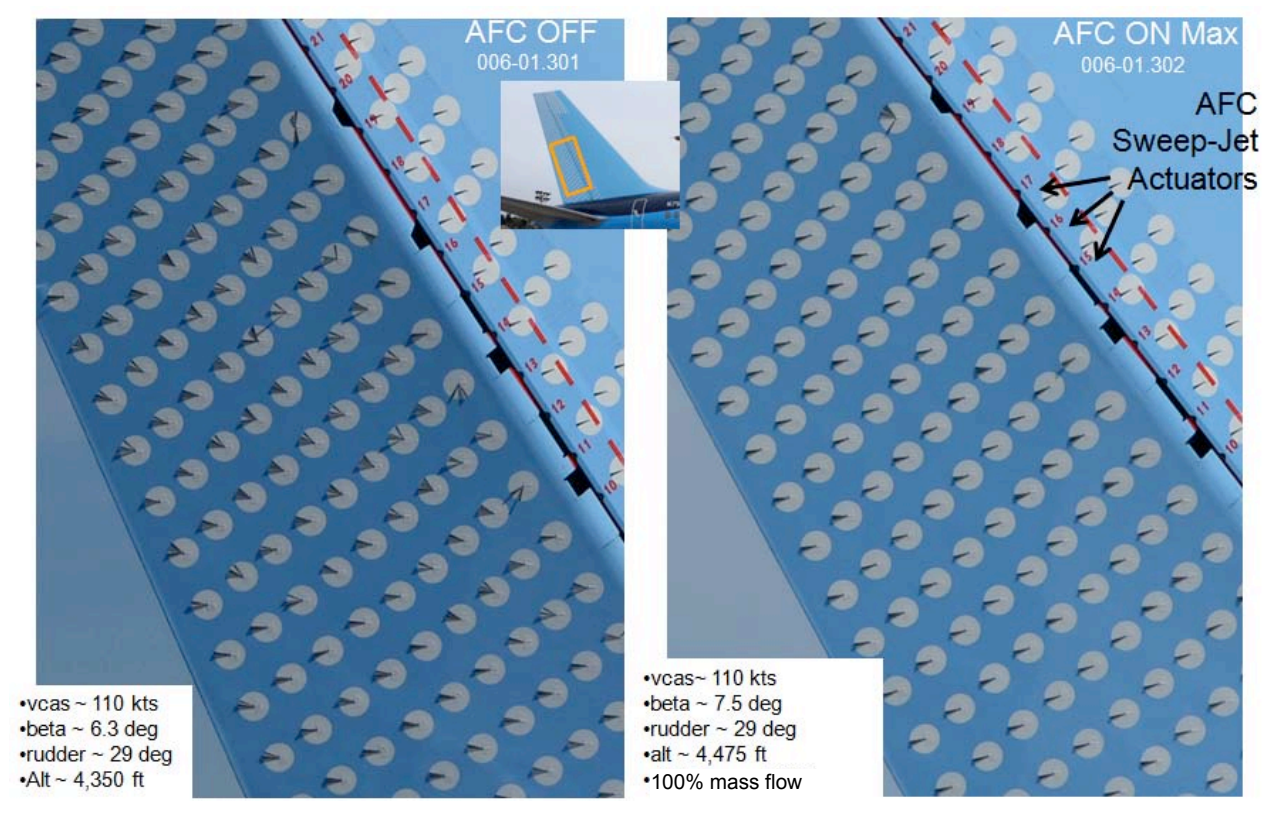

Figure 14. Composite pictures of flow cones with AFC off (left) and on (right) for the flight conditions indicated in the lower left corner.

Figure 15 indicates the increased reduction in flow-cone unsteadiness in the mid-span aft region of the rudder as AFC mass flow rate is increased from $50 \%$ to $100 \%$. Overall, the flow cones on the vertical tail confirm the AFC system reduces flow separation at high rudder deflections.

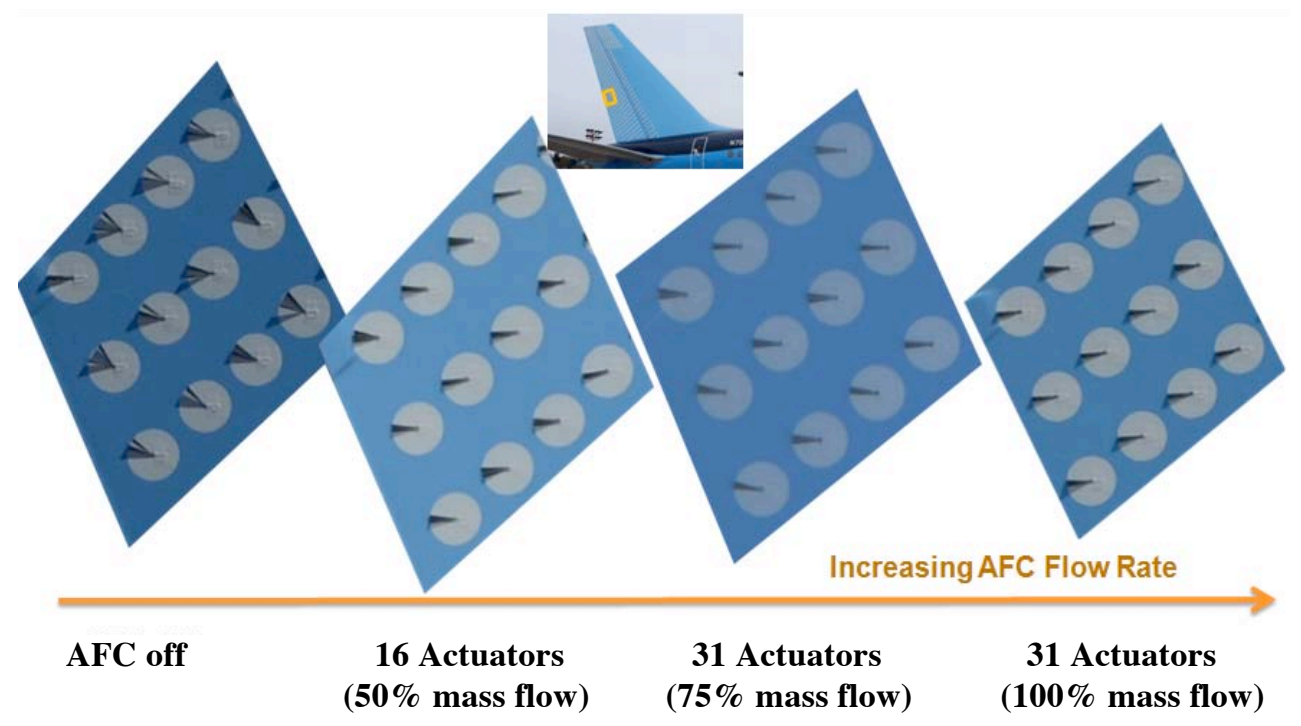

Figure 15. Magnified rudder composite photos and flow rates ranging between AFC off and maximum flow.

AFC effects on yawing moment, side force and rudder power were derived from the flight test data by applying Boeing proprietary methods to update the standard $757 \mathrm{flight}$ simulation model. The analysis accounted for the asymmetrical wing geometry, AFC heat exchanger, and the AFC actuators on the right-hand side of the vertical fin as present on the baseline 757 ecoDemonstrator aircraft. Residuals relative to the standard 757-simulation model were adjusted to be similar between AFC-on and AFC-off flight-test cases. As a result, changes in rudder effectiveness due to AFC are isolated from asymmetries present in the 757 ecoDemonstrator baseline configuration.

Figure 16 summarizes the relative increments in rudder effectiveness at various rudder deflections as a function of $\beta$ for the 31 -actuator case at the maximum flow rate (100\% mass flow). Note that in this figure, the rudder increments are shown in piecewise linear segments between "break points" used in constructing the multidimensional parameter space (i.e., $\beta$, rudder deflection, mass flow rate). 


\section{Critical $\beta$ range}

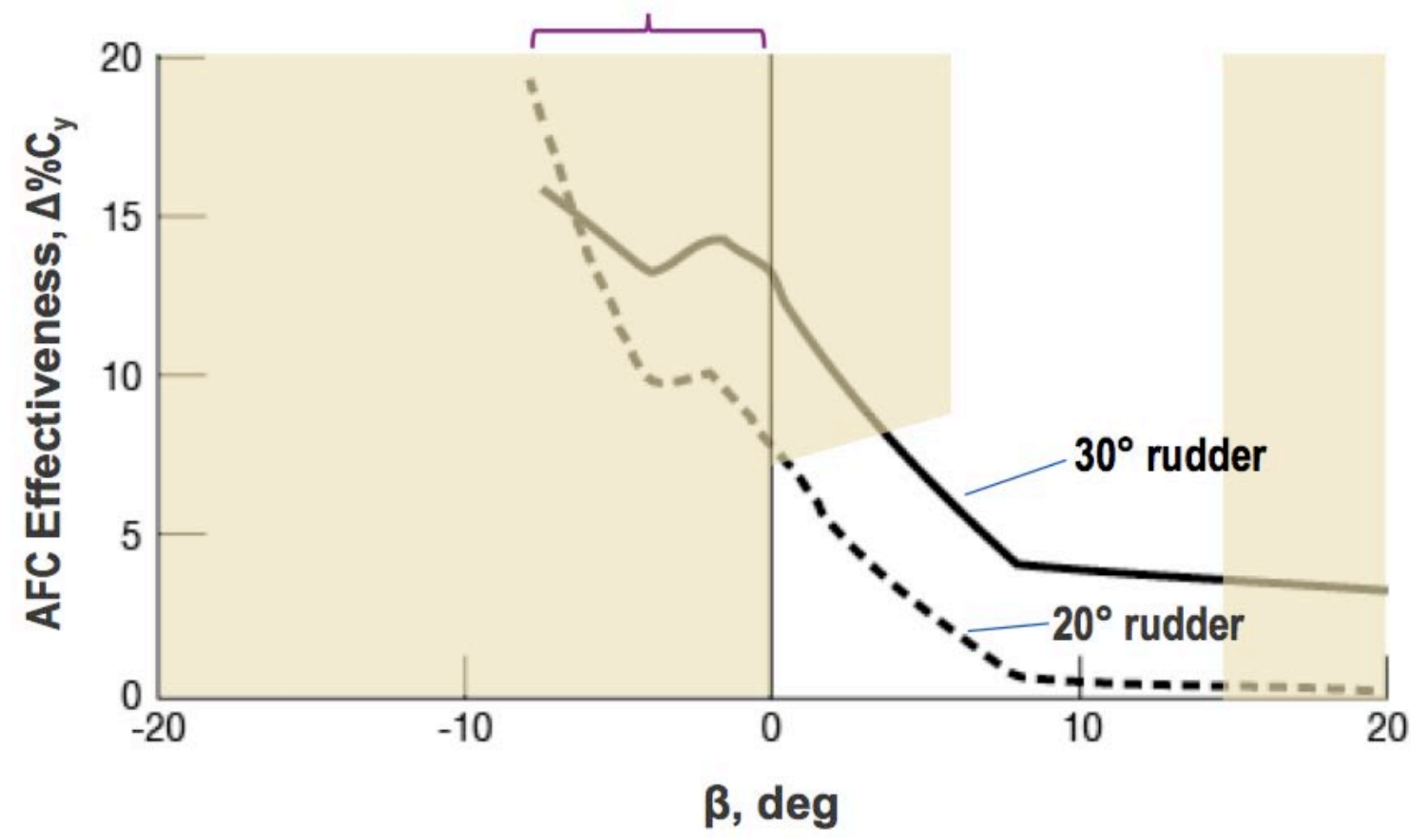

Figure 16. Predicted 757 ecoDemonstrator percentage increase in rudder effectiveness due to AFC based on flight test and full-scale wind tunnel data (31 Actuators, $100 \%$ mass flow). Shaded area: no flight test data available.

These flight test results obtained within the 757 ecoDemonstrator testing envelope demonstrate a sizeable AFC benefit in rudder effectiveness. The test results indicate a $6 \%$ improvement at $30^{\circ}$ rudder deflection $\left(\beta\right.$ near $\left.+5^{\circ}\right)$. At a given $\beta$, AFC impact on rudder effectiveness increases as rudder deflection increases towards $30^{\circ}$. Consistent with expectation, the impact of AFC significantly increases as $\beta$ approaches zero and negative sideslip angles. Based on these flight test data and full-scale wind tunnel data, a side force increase of $13 \%$ to $16 \%$ was estimated at $30^{\circ}$ rudder deflection for critical sideslip range between $\beta=0^{\circ}$ and $-7.5^{\circ}$. A prior Boeing system study indicated a side force enhancement of similar magnitude could produce an estimated fuel burn reduction of 15,500 gallons/airplane/year. ${ }^{15}$

\section{Concluding Remarks}

A NASA/Boeing research effort to develop AFC technology to enhance aerodynamic efficiency of a vertical tail was successfully executed on subscale and full-scale models as well as in flight. It was a complex multiorganizational and multidisciplinary team effort. The subscale test was performed at Caltech with the financial support of the NASA ERA project, where more than 50\% side force enhancement was achieved by the sweeping jet actuation when the momentum coefficient was $1.7 \%$. Subsequently, a full-scale Boeing 757 vertical tail model equipped with sweeping jet AFC technology was tested at the NFAC 40x80 wind tunnel. NASA contributed, with the support of Caltech and the University of Arizona, to the sweeping jet AFC system and the wind tunnel test time. Boeing contributed the flight hardware vertical tail model that was refurbished and equipped with sweeping jet actuators. Flow separation control testing was performed at a nominal speed of 100 knots, up to a maximum rudder deflection of $30^{\circ}$, and sideslip angles that covered the vertical tail flight envelope. A 31-actuator AFC configuration produced significant flow attachment on the rudder, which resulted in $20 \%$ and greater increases in side force for the maximum rudder deflection of $30^{\circ}$ at $0^{\circ}$ and $-7.5^{\circ}$ sideslip angles. Leveraging the knowledge gained from the fullscale test, the AFC-enhanced vertical tail technology was flown on the Boeing 757 ecoDemonstrator in the spring of 2015. The flight test was considered a resounding success. The chase plane observer noted that the flow cones on the rudder indicated strong flow alignment (flow attachment) along the rudder span with the AFC turned on, as 
opposed to massive flow separation observed for AFC off. Pilot feedback and an initial analysis of the flight data confirmed that the AFC is effective, as smoother flight and enhanced rudder control authority were achieved. A side force increase of $13 \%$ to $16 \%$ was estimated at $30^{\circ}$ rudder deflection for critical sideslip range between $\beta=0^{\circ}$ and $7.5^{\circ}$ with the activation of AFC.

\section{Acknowledgments}

This multi-organizational and multidisciplinary teaming effort involved many people who provided valuable contributions through their detailed work and/or expert guidance. The contributors have come from within the NASA/Boeing team and their partners. The NASA/Boeing collaboration was executed through three Space Act Agreements for subscale test at Caltech, full-scale test at NFAC, and flight test (Annex 2 to SAA1-1018, Annex 8 and Annex 9 to SAA1-1155, respectively). The NASA ERA project sponsored the sweeping jet AFC technology via Caltech (TEAMS Contracts NNL10AM26T and NNL12AA09C) and the University of Arizona (direct subcontract). The ERA project also sponsored the wind tunnel test at NFAC (NIPR\# NNL12AA13T) and the flight test (SMAAART Contract NAS1-NNL10AA05B, Tasks NNL13AC06T and NNL14AA57T). Boeing also sponsored the initial synthetic jet AFC vertical tail research at RPI. The authors would like to thank all those who involved for their great support during the course of this technology development.

\section{References}

${ }^{1}$ Collier, F. S., Thomas, R., Nickol, C. A., Lee, Chi-Ming, and Tong, M., "Environmentally Responsible Aviation - Real Solutions for Environmental Challenges Facing Aviation," 27th International Congress of the Aeronautical Sciences, Paper No. 802, Nice, France, September 19-24, 2010.

${ }^{2}$ Bezos-O'Conner, G. M., Mangelsdorf, M. F., Maliska, H. A., Washburn, A. E., and Wahls, R. A., "Fuel Efficiencies Through Airframe Improvements," AIAA 2011-3530, 29th AIAA Applied Aerodynamics Conference, Honolulu, HI, June 27-30, 2011.

${ }^{3}$ Cattafesta III, L. N. and Sheplak, M., "Actuators for Active Flow Control," Annual Review of Fluid Mechanics, Vol. 43, Issue 1, August 2010, pp. 247-272.

${ }^{4}$ Rathay, N., Boucher, M., Amitay, M., and Whalen, E., "Performance Enhancement of a Vertical Stabilizer using Synthetic Jet Actuators: No Sideslip," AIAA 2012-0071, 50th AIAA Aerospace Sciences Meeting, Nashville, TN, January 9-12, 2012.

${ }^{5}$ Rathay, N., Boucher, M., Amitay, M., and Whalen, E., "Performance Enhancement of a Vertical Stabilizer using Synthetic Jet Actuators: Non-zero Sideslip," AIAA 2012-2657, 6th AIAA Flow Control Conference, New Orleans, LA, June 25-28, 2012.

${ }^{6}$ Rathay, N., Boucher, M., Amitay, M., and Whalen, E., "Parametric Study of Synthetic-Jet-Based Control for Performance Enhancement of a Vertical Tail," AIAA Journal, DOI: 10.2514/1.J052887, May 2014.

${ }^{7}$ Raman, G. and Raghu, S., "Cavity Resonance Suppression Using Miniature Fluidic Oscillators”, AIAA Journal, Vol. 42, No. 12, December 2004, pp. 2608-2611.

${ }^{8}$ Seele, R., Graff, E., Gharib, M., Taubert, L., Lin, J., and Wygnanski, I., "Improving Rudder Effectiveness with Sweeping Jet Actuators," AIAA 2012-3244, 6th AIAA Flow Control Conference, New Orleans, LA, June 25$28,2012$.

${ }^{9}$ Seele, R., Graff, E., Lin, J., and Wygnanski, I., "Performance Enhancement of a Vertical Tail Model with Sweeping Jet Actuators," AIAA 2013-0411, 51st AIAA Aerospace Sciences Meeting, Grapevine, Texas, January 7$10,2013$.

${ }^{10}$ Graff, E., Seele, R., Lin, J., and Wygnanski, I., "Sweeping Jet Actuators - A New Design Tool for High Lift Generation," NATO Workshop on Innovative Control Effectors for Military Vehicles (AVT-215), Stockholm, Sweden, May 20-22, 2013.

${ }^{11}$ Whalen, E. A., Lacy, D., Lin, J. C., Andino, M. Y., Washburn, A. E., Graff, E. C., and Wygnanski, I., "Performance Enhancement of a Full-Scale Vertical Tail Model Equipped with Active Flow Control," AIAA Paper No. 2015-0784, 53 ${ }^{\text {rd }}$ AIAA Aerospace Sciences Meeting, Kissimmee, FL, January 5-9, 2015.

${ }^{12}$ Andino, M. Y., Lin, J. C., Washburn, A. E., Whalen, E. A., Graff, E. C., and Wygnanski, I., "Flow Separation Control on a Full-Scale Vertical Tail Model using Sweeping jet Actuators," AIAA Paper No. 2015-0785, 53 ${ }^{\text {rd }}$ AIAA Aerospace Sciences Meeting, Kissimmee, FL, January 5-9, 2015.

${ }^{13} \mathrm{http}: / /$ www .engadget.com/2015/04/03/nasa-boeing-era-eco-friendly-planes/

${ }^{14} \mathrm{http}$ ///rotorcraft.arc.nasa.gov/Research/facilities/windtunnels.html

${ }^{15}$ Mooney, H. P., Brandt, J. B., Lacy, D. S., and Whalen, E. A., “AFC-Enabled Vertical Tail System Integration Study," NASA/CD-2014-218168, March 2014. 